\title{
Encontros entre prática de pesquisa e ensino: oralidade e letramento no ensino da escrita*
}

\author{
Manoel Luiz Gonçalves Corrêa**
}

\section{Resumo}

Neste trabalho, parte-se do processo de constituição dos gêneros discursivos, tomando-se como noção teórica central a de relaçôes intergenéricas (BAKHTIN, 1992). Tipos de letramentos, oralidade e heterogeneidade da escrita são os recursos pelos quais se investiga tanto o uso de provérbios parodiados na internet e em redaçóes de vestibular, quanto o uso de temporalidades de diferentes ordens no processo de constituiçáo dessas redaçóes. Como resultado, evidencia-se a produtividade do encontro entre prática de pesquisa e ensino, mesmo que se reconheça que o tratamento teórico-metodológico do objeto de pesquisa não se transfere como tal para a atividade de ensinar.

Palavras-chave: Oralidade. Escrita. Prática de ensino. Pesquisa.

* Uma primeira versão deste trabalho foi apresentada como parte da mesa redonda "Linguagem em atividade no ensino de língua materna", no $58^{\circ}$ Seminário do GEL (SEMINÁRIO..., 2010).

** Professor do Departamento de Letras Clássicas e Vernáculas da Faculdade de Filosofia, Letras e Ciências Humanas da USP e pesquisador do CNPq. 


\section{Introdução}

Os caminhos da Linguística Aplicada em relação ao tratamento da linguagem no ensino de língua materna têm sido vários. Neste trabalho, limito-me a retomar alguns resultados de minha própria pesquisa, centrada na convivência entre práticas orais e letradas no texto escrito. Pretendo observar possíveis encontros entre prática de pesquisa e ensino da escrita, mesmo reconhecendo que o tratamento teórico-metodológico do objeto de pesquisa não se transfere como tal para a atividade de ensinar.

Perspectivas enunciativas como a de filiação bakhtiniana, assim como a perspectiva discursiva sobre a linguagem, podem resultar num recurso, tanto na pesquisa quanto no ensino, para tratar do cruzamento entre práticas orais e letradas no texto escrito. Trata-se, pois, de um encontro produtivo entre prática de pesquisa e ensino. A questão central de que parto não é, propriamente, a do trabalho com gêneros do discurso cristalizados, mas com o processo de sua constituição, tomando como noção central à de relaçóes intergenéricas (BAKHTIN, 1992). O exemplo escolhido passa pelo comentário de provérbios parodiados para chegar à escrita de préuniversitários em situação de vestibular. Se vistos como registros da relação que o sujeito mantém com o já-dito, e não, simplesmente, como marcas de fragmentação ou de falta de coerência, podem-se levantar hipóteses sobre as relaçôes intergenéricas (BAKHTIN, 1992) que, em jogo na construção textual, marcam uma história de contato com o já-falado/escrito. Como resultado, o encontro entre prática de pesquisa e ensino pode, pois, ser exemplificado pelo acesso à história de relação do escrevente com o já-falado/ escrito, já que auxilia na tomada de decisóes didáticas em sala de aula.

No que se refere, portanto, à convivência entre práticas orais e letradas no texto escrito, entendo-a como uma das características da heterogeneidade da escrita. Refiro-me, naturalmente, à escrita alfabética e é em relação a ela que defendo a ideia de que a escrita é heterogênea no que tange à relação entre práticas orais e práticas letradas.

\section{Observações teóricas prévias sobre a heterogeneidade da escrita}

Para o presente trabalho, optei por caracterizar a heterogeneidade da escrita, partindo de quatro características da noção de letramento. Antes 
de indagar sobre a relação entre práticas letradas e práticas orais, exponho, portanto, essas quatro características da noção de letramento.

A primeira delas consiste na afirmação de Street $(1995,2006)$ de que há letramentos, no plural, e não um único tipo de letramento, normalmente identificado com aquele das práticas escritas com base na alfabetização. Como se sabe, a escrita pensada como autônoma, descontextualizada e pura na sua relação com as práticas orais/faladas ${ }^{1}$ é fonte de numerosos equívocos no ensino. Vale, pois, registrar um esclarecimento sobre a autonomia da escrita.

Ao mencioná-la, refiro-me à proposição de Olson (1977) de que a técnica ensaística britânica, desenvolvida a partir do surgimento da imprensa, teria, historicamente, constituído uma modalidade escrita inteiramente autônoma em relação à língua oral. Refiro-me, também, à posição de Ong (1998). Essa visão, já tradicional, continua a fazer seguidores. Mais recentemente, Bajard (2006, p. 498), baseando-se em Ong, defende a mesma ideia:

O alfabeto nasceu da transposição dos fonemas em letras por meio de várias metamorfoses. Os gregos, assumindo radicalmente o aspecto fonético da escrita (século IX a.C.) suprimiram o espaço entre as palavras, presente na escrita fenícia, uma vez que o espaço não correspondia a nenhum som, fazendo prevalecer uma escrita perfeitamente alfabética, a scriptio continua, com correspondências biunívocas entre grafemas e fonemas (SAENGER, 1998). Na Idade Média, a partir do século IX, foi reintroduzido o espacejamento entre as palavras e, mais tarde, a minúscula e a pontuação. Uma dimensão ideográfica foi desse modo incorporada à lógica puramente alfabética, dado que o acesso ao texto, que até então ocorria por meio de sua oralização, passou a ser também visual, ou seja, silencioso, sem depender da pronúncia. Essas mudanças contribuíram para a autonomia da 
escrita - hoje reconhecida - em relação à língua oral. (ONG, 1998).

De minha parte, embora considerando a argumentação desses autores, preocupo-me em flagrar a falta de autonomia da escrita em relação à fala no próprio processo de escrita: da mesma forma que, nesse processo, o aspecto visual da escrita é mobilizado, a característica da íntima relação escrita/fala, presente em sua gênese, vem frequentemente à tona, fazendo intervir, além disso, outras vinculaçóes entre diferentes práticas orais e letradas. Esse tipo de emergência da gênese da escrita, rotineiramente flagrado pelos professores e identificado como "interferência da fala na escrita", mostra que, no processo de escrita, são retomados, com frequência, aspectos de sua gênese, marcando seu estatuto não autônomo em relação à fala e às práticas sociais em que a oralidade é requisitada. Ao evidenciar que sua estabilidade é contingencial, a consideraçáo do processo de escrita póe, portanto, em xeque, a ideia de autonomia da escrita tal como defendem Ong e seus seguidores.

A segunda característica da noção de letramento está relacionada com as diferentes formas de manifestação dos vários tipos de letramento. A mais esquecida dessas formas é a própria oralidade, sobre a qual, no entanto, não vou me estender neste trabalho. Restringindo-me a formas de escrita, os letramentos não se manifestam, como se sabe, apenas pela escrita alfabética, mas, também, por exemplo, pelo desenho, pelo gesto, pelos nós, pelos entalhes sobre matéria dura, pelo próprio modo de enunciação da escrita alfabética etc. $\mathrm{Na}$ formulação de Martins (2002), tais manifestaçóes correspondem a diferentes formas de escrita, as quais são, como se sabe, passíveis de variadas combinaçôes, inclusive com o modo de enunciação oral.

Contribuem, também, para a definição da heterogeneidade da escrita, os espaços sociais em que essas manifestaçóes de letramento circulam e se cruzam. A circulação dessas manifestaçóes é, portanto, a terceira característica da noção de letramento que considero importante lembrar.

O desenho, por ser preso a suportes específicos, depende da mobilidade desses suportes para ocupar determinados espaços sociais. Comparem-se as inscriçóes rupestres e as charges, por exemplo. Inversamente, o gesto está potencialmente presente em todos os espaços sociais. Basta lembrar que o seu principal suporte é o próprio corpo humano. Por sua vez, aproximandose, em certa medida, de um dos aspectos do desenho, os nós ${ }^{2}$, quando 
empregados como recurso mnemônico, estão presos a suportes específicos e dependem, também, da mobilidade desses suportes. Comparem-se, por exemplo, um nó no barbante amarrado ao dedo e tomado como recurso mnemônico descartável e os nós feitos em cipó como forma de contar, marcando um letramento quantitativo. Os entalhes, presos a suportes específicos, também dependem da mobilidade desses suportes. Pense-se nos entalhes em diferentes matérias duras, como o barro, a madeira, a pedra. Finalmente, a própria escrita alfabética, presente em quase todos os espaços sociais, é fixável no espaço, flexível em relação ao objeto que apreende e guarda, ainda, o aspecto da visibilidade invariante do produto gráfico. Este último aspecto lhe dá a propriedade de permanecer no tempo, permitindo a fixação da memória de uma dada cultura, de modo a registrar o testemunho, independentemente da presença da testemunha. Não importa que sua visibilidade invariante seja, por vezes, erroneamente interpretada como registro de um sentido invariante, equívoco ligado a uma concepção de leitura como simples decodificação. Características como a de ser fixável no espaço, flexível em relação ao objeto que apreende e invariante no que se refere ao produto gráfico constituem aspectos determinantes da potência dessa tecnologia e do valor que lhe é atribuído.

Como se pode notar, não há espaços sociais privativos para as manifestações dos letramentos por meio de diferentes escritas. Essas manifestações cruzam-se entre si e, também, com o modo de enunciação oral, que está potencialmente presente em todos os espaços sociais e cujo principal suporte é, a exemplo dos gestos, o som da voz, ligado, portanto, ao próprio corpo humano.

A quarta e última característica da noção de letramento para a definiçãao da heterogeneidade da escrita está relacionada à própria escrita alfabética e à relaçáo de autonomia ou náo autonomia dos tipos de escrita em relaçáo à linguagem articulada (FÉVRIER, 1948 apud MARTINS, 2002, p. 33-34). Segundo esse autor, as "formas embrionárias" de escrita são autônomas, pois não dependem da linguagem articulada para estabelecerem a relação linguagem/mundo. São exemplos dessas "formas embrionárias" o desenho, o gesto, os nós, o entalhe sobre matéria dura. Por sua vez, as "formas avançadas" de escrita, como a escrita alfabética, guardam, em sua gênese, uma particularidade: são não autônomas, pois dependem da linguagem articulada para estabelecer a relação linguagem/mundo. A essa 
não autonomia presente na gênese da escrita está ligada, por exemplo, à incorreta identificação entre língua e escrita.

Resumindo: a diversidade de tipos de letramento (para além do domínio da escrita alfabética); suas formas de manifestação (diferentes formas de escrita e suas combinaçóes, inclusive com a própria oralidade); os espaços sociais em que circulam e se cruzam; a não autonomia da escrita alfabética em relação à linguagem articulada (não autonomia mostrada na gênese dessa escrita e nas retomadas dessa gênese no processo de escrita) são alguns elementos que caracterizam a heterogeneidade da escrita.

Cabe, porém, neste ponto, indagar sobre o papel das práticas orais na definição da heterogeneidade da escrita. Com relação a elas, a heterogeneidade da escrita se manifesta na convivência entre práticas sociais ligadas à civilização escrita (um quase sinônimo de "tradição escrita") e à civilização oral - forma pela qual Bonvini (2001) prefere nomear a tradição oral, expressáo que, oposta à sua correspondente "tradição escrita", tem servido para identificar, de modo depreciativo, as sociedades chamadas "primitivas". Entendo por "convivência” entre essas práticas, não o fato de elas não serem excludentes e coexistirem, isto é, não simplesmente em razão de elas manterem relações de vizinhança. Conviver significa, neste caso, ser parte constitutiva uma da outra. É o que, por um lado, pode-se depreender, por exemplo, da não autonomia da escrita, manifestamente presente tanto em sua gênese quanto no processo de escrita; e, por outro lado, das sociedades de oralidade secundária (ONG, 1998), em que a oralidade é, invariavelmente, marcada pela presença da escrita.

\section{Encontros entre práticas de pesquisa e ensino: dois exemplos}

No que se refere ao objetivo central deste trabalho - tematizar o encontro entre práticas de pesquisa e ensino -, a questão de partida que me orienta é uma concepção de texto como registro do processo de sua constituição.

O recurso teórico básico é a noção de gênero do discurso de Bakhtin (1992). O diálogo entre práticas sociais orais e letradas traz, porém, como questáo central para o ensino, náo propriamente o trabalho com gêneros discursivos cristalizados, mas, justamente, com o processo de 
sua constituição, destacando-se como noção teórica central a de relaçóes intergenéricas ${ }^{3}$ (BAKHTIN, 1992), por meio das quais a heterogeneidade da escrita se mostra com clareza.

\section{Primeiro exemplo: provérbios parodiados na internet}

$\mathrm{Na}$ tentativa de aproximar prática de pesquisa e ensino, utilizo o exemplo do provérbio, que trato como um gênero do discurso. De uma lista de provérbios parodiados que têm circulado na internet, seleciono alguns e proponho a análise de apenas um, pois suponho que procedimento de análise semelhante possa ser aplicado aos demais.

Vejamos, então, os seguintes provérbios parodiados que têm circulado na internet:

1) Amigos, amigos, senhas à parte.

2) Não adianta chorar sobre arquivo deletado.

3) Mais vale um arquivo no HD do que dois baixando.

4) Diga-me que chat frequentas e te direi quem és. ${ }^{4}$

Obviamente, há, no provérbio parodiado, um diálogo com os provérbios tradicionais correspondentes:

1a) Amigos, amigos, negócios à parte.

2a) Não adianta chorar sobre o leite derramado.

3a) Mais vale um pássaro na mão do que dois voando.

4a) Diga-me com quem andas e te direi quem és.

Tomemos, pois, o caso de (1):

1) Amigos, amigos, senhas à parte.

e o confrontemos com (1a):

(1a) Amigos, amigos, negócios à parte.

O objetivo é investigar - sem, naturalmente, pretender determinar uma origem - o processo de constituição que ele registra.

Como se pode observar, seu processo de constituiçáo se marca, inicialmente, pelo diálogo entre dois espaços sociais. No provérbio 
parodiado, reconhece-se um espaço social caracterizado por uma nova mídia, um novo suporte e um público mais ou menos definido. Ele registra, portanto, certo espaço social privilegiado. Já o provérbio tradicional, embora circule por espaços sociais através de mais de um meio - pense-se no oral, no escrito e no próprio meio digital -, pode-se dizer que, do ponto de vista de sua publicização, apresenta-se para um público menos definido que o primeiro. Não há, nesse caso, um espaço social privilegiado.

Provisoriamente, podemos dizer que esses provérbios parodiados são constituídos pela atuação de uma nova tecnologia e representam uma nova esfera de atividades, caracterizada, por exemplo, por sua circulação específica por determinado espaço social, constituído, no limite, pelas pessoas que têm acesso ao computador. Trata-se de um espaço amplo e não restrito à circulação pelo campo digital, mas, ainda assim, não cobre a potencial universalidade de espaços dos provérbios tradicionais.

Dando prosseguimento à indagação sobre o processo de constituição dos provérbios parodiados nos diálogos entre práticas sociais, tomemos, desta vez isoladamente, o provérbio (1) e seu correspondente (1a). Observemos, em primeiro lugar, os enunciados que constituem (1a). O que poderíamos dizer sobre o processo de constituição desse provérbio?

(1a) Amigos, amigos $\longleftrightarrow$ negócios à parte.

Em "Amigos, amigos", tematiza-se a amizade. Em "negócios à parte", tematizam-se as transações de caráter comercial, o dinheiro, o lucro, o individualismo. Pode-se, pois, já pelo aspecto temático, observar um diálogo interno ao provérbio: o enunciado proverbial como um todo faz esses temas dialogarem, estabelecendo-se um paralelo entre o valor social atribuído à amizade e o valor social atribuído às vantagens pessoais.

Há, portanto, pelo menos dois campos de atividade dialogando num único e mesmo provérbio. $\mathrm{O}$ tema da amizade poderia definir o campo dos saberes imateriais (preceitos éticos e morais) que sustentam as relações entre as pessoas e que estão presentes na vida cotidiana, filiando-se ao campo da moral, ou ao da moral religiosa, ou mesmo, em certa medida, ao campo jurídico. No enraizamento desse dizer sobre a amizade, podese, pois, reconhecer uma máxima. Essa aproximação a uma máxima não se faz propriamente por um diálogo explícito nem por meio de simples reposição de um tema, mas por meio da recuperação, menos aparente, de 
um dizer impregnado pelos seus usos. Trata-se, no sentido bakhtiniano, de um enunciado concreto, cuja realização está ligada, portanto, a esferas determinadas de atividade humana.

Por sua vez, em "negócios à parte", o tema do lucro define o campo da propriedade material, o salve-se-quem-puder da busca das vantagens e do sucesso pessoais. Esse campo sustenta, entre outras coisas, as relaçóes de negócio entre as pessoas - com marcado individualismo - e se filia, grosso modo, ao campo da economia. A exemplo do primeiro enunciado e num funcionamento semelhante, este último marca a atuação da estrutura de uma máxima. Uma vez mais, não se trata de uma simples referência a um tema, mas da reposição de um dizer impregnado pelos seus usos, marcado, como no primeiro caso, por claro engajamento ideológico. Em termos bakhtinianos, trata-se, em função de sua realização estar ligada a certa esfera de atividade humana, de um enunciado concreto.

Não é difícil constatar que, nessa relação entre as duas máximas constituintes do provérbio, os dois campos se hierarquizam em favor do segundo, o que evidencia não apenas o aspecto dialógico que constitui o provérbio, mas o tipo de dialogia proposta entre as máximas. Desse modo, ao aspecto composicional da presença de máximas num provérbio, acrescenta-se o da hierarquização valorativa do "lucro pessoal" em relação à "amizade", sendo essa hierarquização outro aspecto importante do processo de constituição do provérbio.

Tomado como indicador inquestionável das direções das ações humanas, o provérbio põe, portanto, em relação hierárquica, diferentes saberes provenientes de diferentes esferas de atividade. Sua repetição, assumida como a reiteração de um percurso a ser seguido, tem a força de orientar os comportamentos sociais.

No provérbio parodiado, acontece um processo semelhante de constituição.

(1) Amigos, amigos $\leftarrow \rightarrow$ senhas à parte.

Reiterando o provérbio tradicional, "Amigos, amigos” tematiza a amizade por meio de um enunciado que já é uma máxima. Quebrando, porém, a expectativa, o enunciado seguinte "senhas à parte" tematiza não propriamente as vantagens pessoais, mas um modo de a pessoalidade se 
constituir, isto é, pela privacidade. Esse tema passa por vários campos da intimidade, desde o econômico até o amoroso, de tal modo que o aspecto do lucro pessoal (o dos "negócios") que nele ecoa não se restringe, desta vez, ao campo econômico, mas ao horizonte de aparecimento do próprio indivíduo. Para fazê-lo, o enunciado "senhas à parte" mantém a estereotipia rítmica do provérbio tradicional, mas quebra a sua estereotipia semântica, redefinindo $\mathrm{o}$ arco de sentido que abarca. A manutenção da estereotipia rítmica induz a pensar que sua enunciação comporta, também, uma máxima e que esta é tâo aceita quanto a sua correspondente do provérbio tradicional. Portanto, a exemplo do enunciado "Amigos, amigos", este último - mesmo que não o faça do mesmo modo que no provérbio tradicional - deixa ao menos entrever a atuação da estrutura de uma máxima. Neste caso, o efeito de máxima fica entrevisto, pois o enunciado "senhas à parte" remete a uma forma fixa que nele ecoa: "negócios à parte”, que, sendo de conhecimento público, permanece presente mesmo tendo sua estereotipia em parte rompida. Por sua vez, o efeito dessa ruptura atinge não só o tema, mas também o campo social (e de saber) de sua repetibilidade.

Desse modo, no que se refere ao processo de constituição do provérbio parodiado, ao lado da relação dialógica entre provérbios e internamente ao provérbio; ao lado da nova "língua" que nele ganha espaço; ao lado da quebra da estereotipia; ao lado da presença ativa do sujeito que o produz, justamente num enunciado supostamente pouco propício a intervençóes (POSSENTI, 2002), constata-se algo que se mantém. Trata-se de um aspecto da conversão da palavra alheia (no caso, o provérbio tradicional) em palavra própria ${ }^{5}$ (no caso, o provérbio parodiado). Esse aspecto que se mantém assemelha-se ao que White (1992) chama de "conteúdo da forma"6. Quero dizer, com isso, que há um aspecto formal que é reiterado no provérbio parodiado. Trata-se do ritmo dos enunciados componentes que, ao organizar a heterogeneidade ${ }^{7}$ desse texto, registra a presença da palavra alheia (representada pelo provérbio tradicional) na palavra própria (representada pelo trabalho do sujeito no provérbio parodiado), palavra alheia que é presença constitutiva no uso da linguagem em geral e, em particular, na retomada dos provérbios.

Nesse sentido, embora o provérbio parodiado como um todo se baseie, à primeira vista, apenas no domínio de uma nova tecnologia e de um campo de saber determinado, ele, a exemplo do seu correspondente tradicional, faz duas máximas dialogarem. Além disso, ele também estabelece um paralelo 
entre o valor social atribuído à amizade e o valor social atribuído a uma concepçáo de individualidade que se afirma pela privacidade. De onde se pode concluir que há aspectos do provérbio tradicional, tomado como representante da palavra alheia, que se mantêm no trabalho que o sujeito faz ao produzir o provérbio parodiado. Ou seja, o provérbio parodiado por meio de "senhas à parte" mantém ecos do enunciado "negócios à parte" e, também, dos efeitos de sentido do provérbio tradicional como um todo, tal como o da preferência pelo que é privativo, individual.

Cabe, neste ponto, indagar sobre qual a relação entre os provérbios parodiados e a heterogeneidade da escrita.

Em primeiro lugar, esse texto, que nasceu escrito (e na internet), provém de um provérbio que tanto pode ser de procedência escrita quanto falada, mantendo, assim, um traço particular desse gênero. Entre o escrito e o falado, a heterogeneidade do provérbio, como gênero do discurso, é flagrante, pois se é encontrável nas máximas religiosas bíblicas e, assim, passível de pertencer à civilização escrita, é também de fácil memorização e pode também ser atribuído à civilização oral. Além disso, a própria condição de emergência do provérbio, pensado como um gênero do discurso, fundamentase no estabelecimento de relaçóes intergenéricas, à medida que ele congrega enunciados que apresentam, isoladamente, valor de máximas. Finalmente, o uso dos provérbios não é apenas o uso lúdico que acabo de exemplificar. Há um uso "a sério", mas modificado ${ }^{8}$, dos provérbios; por exemplo, seu uso por alunos em textos escolares.

Ao aproximar a descrição do processo de constituição do provérbio parodiado ao uso "a sério" feito por pré-universitários em situação de avaliação no vestibular, pretendo marcar mais um encontro entre práticas de pesquisa (fundamentada, no caso da análise dos provérbios parodiados, em uma prática de pesquisa de filiação bakhtiniana) e ensino.

Para tanto, recorro a um exemplo que faz parte do corpus de meu projeto de pesquisa no $\mathrm{CNPq}$ Letramento e oralidade na escrita de universitários e pré-universitários: tempo e temporalidade, exemplo que foi analisado por Glauce de Oliveira Alves em seu trabalho de iniciação científica, por mim orientado. 


\section{Segundo exemplo: provérbio e heterogeneidade da escrita}

Impóe-se, neste ponto, um esclarecimento sobre o material a ser referido, composto de redaçóes de vestibular. Esse esclarecimento refere-se à nomeação dos textos produzidos em situação de vestibular como gêneros do discurso.

Em primeiro lugar, quando refletimos sobre o produtor do texto na situação de vestibular de uma universidade pública como a Universidade de São Paulo, deve-se levar em conta mais do que apenas a situação (e a atividade) de avaliação e, também, mais do que seu desempenho verbal escrito. Além do conhecido investimento econômico, ou, até mesmo, em razão dele, há todo um aparato pedagógico que envolve o produtor do texto. No que se refere ao investimento econômico, o número significativo de candidatos que se expóem à prova não esconde a seletividade pré-vestibular decorrente da impossibilidade econômica de preparação para o exame e, até mesmo, de candidatura a ele. No tocante ao aparato pedagógico, ele se materializa em instituiçóes escolares, livros didáticos, manuais de redação, gramáticas, manuais de Linguística (especialmente de Linguística Textual), em especialização de professores. A seleção pré-exame se marca, também, quanto ao acesso dos pré-universitários a esse aparato e, nesse sentido, a inclusão ou exclusão dos potenciais candidatos está diretamente ligada à situação econômica de cada um deles. Outros candidatos potenciais desistem de concorrer em virtude da avaliação negativa que fazem de sua própria formação escolar, atribuída às deficiências da escola pública no ensino básico. Enfim, do ponto de vista do produtor do texto, há muito mais do que apenas desempenho verbal escrito: há tempo despendido, há dinheiro gasto, há expectativas da família e da(s) escola(s), há projetos de futuro profissional em jogo. Portanto, na qualidade de evento cercado por uma série de preocupações institucionais, por um lado, e pessoais, por outro, a específica manifestação de linguagem produzida está vinculada a um rito de passagem, constituindo, por sua abrangência (inclusiva ou não), uma esfera de atividade humana no interior do campo do ensino.

No que se refere ao produto verbal avaliado, só mais recentemente os exames vestibulares têm tido a preocupação em discernir "tipos de texto" de gêneros do discurso. Os tipos argumentativo - presente na dissertação 
e na carta (gênero do discurso também solicitado) - e narrativo têm sido os privilegiados na avaliação de pré-universitários em situaçáo de exame para ingresso nas principais universidades públicas do país. Nesse sentido, duas objeções poderiam ser feitas à nomeação das redações de vestibular como um gênero do discurso, ambas, segundo o que penso, relacionadas a concepçóes mais restritas da atividade verbal e, também, mais limitadas ao estritamente verbal. Por um lado, a ênfase em "tipos" mais do que em gêneros do discurso talvez não permitisse chamar a manifestação de linguagem que os recobre como um "gênero do discurso". Por outro lado, de uma perspectiva etnograficamente orientada, talvez pudéssemos definir o evento vestibular como uma atividade, em que se situariam todas as restriçóes do gênero, o que, como contrapartida, poderia levar, no momento de olhar para os textos produzidos, a uma visada limitada ao estritamente linguístico ou, na melhor das hipóteses, à sua estrutura composicional.

No entanto, considerando:

- a interação social específica (avaliado/avaliador) válida para todos esses textos;

- o comportamento verbal semelhante mesmo na produção de tipos diferentes;

- as escolhas temáticas filtradas por um interesse educacional (os textos são escritos sobre temas relevantes da atualidade); e

- as soluçóes estilísticas essencialmente ligadas ao diálogo com a instituição avaliadora que comportam; pode-se, de maneira operatória e sem pretensão classificatória, dizer que o conjunto dessas restriçóes configura um gênero do discurso que vem sendo especificado pelo predomínio de certos tipos de texto, como, por exemplo, o dissertativo e o narrativo.

Teríamos, então, tipos - predominância do dissertativo ou narrativo, combinados em diferentes proporçóes - produzidos como gênero redação de vestibular. De modo semelhante, a carta, que é um gênero do discurso, seria, no contexto do vestibular, uma proposta de escrita de um tipo argumentativo particular - aquele com interlocução explícita -, produzida, ela também, como gênero redaçáo de vestibular.

Mesmo considerando essas características, este trabalho não tem, contudo, preocupação meramente classificatória e opera com a noção de 
gênero do discurso em função de sua produtividade no reconhecimento do processo de constituiçáo do texto, modo de repor o encontro do produtor do texto com seu produto - encontro, este, fundamental para o ensino.

No vestibular FUVEST de 2006, o tema da redação foi "o trabalho". A ênfase na definição de trabalho, presente na coletânea de textos fornecida no exame e nas instruçóes que se seguiam a ela, acabou resultando, da parte dos candidatos, em inúmeras tentativas de definição do que seria "trabalho". Nesse contexto, com o intuito de servirem como reafirmação das definiçóes privilegiadas pelo escrevente e/ou como argumentos na defesa de um dado ponto de vista, muitos provérbios foram apresentados nos textos, fato que justificou, inclusive, a investigação feita por Alves (2008, p. 64, grifo no original) de cujo relatório de iniciação científica, extraí o seguinte exemplo:

[...] E o trabalho, por mais necessário que seja à sobrevivência humana, é só mais um "aparthaid-nãoracial" inventa-se novas e mais bonitas formas de se dizer que somos feudais sempre mais do mesmo; e, agora, se antes era pela salvação divina, é sob o prisma demagógico do neo-liberalismo: hoje, quem trabalha muito, amanhã será rico!

Compare-se o enunciado destacado:

"hoje, quem trabalha muito, amanhã será rico."

com uma sua variação, numa ordem talvez mais convencional:

"Quem muito trabalha hoje rico será amanhã."

É interessante observar, preliminarmente, que não há correspondência perfeita entre a estrutura dessas duas expressóes proverbiais e a dos provérbios comentados no primeiro exemplo. A alternância rítmica entre a primeira e a segunda parte da expressão proverbial destaca, desta vez, não enunciados independentes, mas a oposição temporal entre "hoje" e "amanhâ". Curiosamente, foram esses os dois elementos destacados na utilização feita pelo escrevente em: "boje, quem trabalha muito, amanhá será rico" (Grifo meu).

Com relação a esse trabalho do escrevente, em certa medida, também parodístico, podem-se observar: 
- relações dialógicas entre provérbios (por exemplo, com: Ganharás o páo com o suor do teu rosto; Deus ajuda quem cedo madruga etc.) e internamente ao provérbio, fazendo dialogar, por um lado, a ética do trabalho, aplicada ao presente; e, por outro, a da recompensa pela riqueza, projetada para o futuro;

- quebra da estereotipia;

- presença ativa do sujeito que o produz, atuando sobre um enunciado supostamente pouco propício a intervençóes.

No entanto, se retomarmos o que foi observado anteriormente sobre o provérbio parodiado, temos:

- a nova "língua" trazida nesse caso não tem relação com um vocabulário específico, como o da internet, mas com o do próprio escrevente;

- a quebra da estereotipia investe, neste caso, numa característica cara aos enunciados proverbiais, isto é, quebra-se o paralelismo rítmico entre a primeira e a segunda parte do enunciado;

- essa quebra é tanto mais interessante quanto se aproxima do tom de uma argumentação coloquial, em que um modo de falar próprio interfere naquilo que seria a forma estereotipada (e esperada) de dizer.

Portanto, em "hoje, quem trabalha muito, amanhã será rico", a relação do sujeito com a linguagem (ABAURRE; FIAD; MAYRINK-SABINSON, 1997) vem claramente caracterizada pela quebra de um dado de estereotipia fundamental dos provérbios, o padrão rítmico de suas partes e entre elas. No entanto, isso é feito em contraposição à estereotipia de sentido, que é mantida. Essa reiteração semântica acontece, porém, já sob um modo de dizer pessoal - mais próximo de gêneros falados (como o diálogo cotidiano) do que do gênero que está sendo produzido pelo escrevente. A reposição da estereotipia corresponde, em termos discursivos, ao estabelecimento de uma relação causal entre trabalho (e preparação para o futuro) e sucesso, ligando, com ironia, a ética do trabalho à ética utilitarista da recompensa.

Eis, pois, na dissertação produzida como gênero redação de vestibular, o trabalho do escrevente com um dizer proverbial, novo exemplo de como a prática de pesquisa, baseada, também neste caso, nas relaçóes 
intergenéricas, possibilita observar aspectos do processo de constituição do texto, contribuindo para a tomada de decisóes no ensino.

A utilização de provérbios pelos escreventes não é, porém, o único exemplo. Apenas para mencionar em breve comentário, é bastante frequente o trabalho do escrevente com as temporalidades. Em Corrêa (2008 e 2010), procurei mostrar que, também do ponto de vista dos arranjos temporais que organizam o texto, o processo de constituiçáo dos gêneros pode vir à tona.

Trabalhando com a oposição entre educação formal, não formal e informal (AFONSO, 2001), argumentei na direção de que a combinação de temporalidades de diferentes ordens é um modo de organizar o texto que não se deve apenas à irrupção de saberes dos campos da educação não formal (educação sistemática obtida fora do sistema formal de ensino) e informal (educação ligada à experiência cotidiana, no círculo familiar, dos amigos, do trabalho etc.). Pelo contrário, naqueles trabalhos, defendo a ideia de que o modo de transmissão oral dos saberes em sala de aula é, também - em função das características didáticas que assume -, um forte indutor da emergência de saberes desse tipo. Portanto, mesmo na educação formal, sustentada pelo sistema formal de ensino - cursinhos preparatórios para o vestibular incluídos -, há o cruzamento de vários tipos de saber, fato que permite definir a combinação de temporalidades de diferentes ordens como um dos elementos do processo de constituição do gênero redação de vestibular (CORRÊA, 2008; 2010).

\section{Considerações finais}

Inicio estas consideraçóes finais por algumas observaçóes teóricas para, em seguida, sintetizar os resultados deste trabalho.

Barré-de-Miniac (2006, p. 52), descrevendo, com precisão, o tratamento do ler/escrever no plano da pesquisa, afirma que "os trabalhos sobre o ler e o escrever tendem a ampliar o campo das investigaçóes. O ler/ escrever não é mais tratado apenas sob o ângulo do ensino/aprendizagem, mas também em termos de práticas e de contextos de uso."

Atentos às práticas sociais e aos contextos de uso, Lea e Street (2006) propóem três perspectivas ou modelos para as abordagens da escrita e do letramento do estudante em contextos universitários. Esses modelos, que se sobrepóem, são: 
- o modelo das habilidades;

- o modelo da socialização acadêmica; e

- o modelo de letramentos acadêmicos.

Em trabalho sobre artigos acadêmicos e particularizando suas observaçóes para o terceiro modelo, Street (2009) trata de certos aspectos que permanecem ocultos quando os estudantes são orientados sobre suas escritas, tais como, a objetividade ao estabelecer os propósitos de um ensaio, por exemplo; a preocupação com explicitar a contribuição do trabalho; o grau de envolvimento marcado pela inscrição da voz de quem escreve etc.

Em função do que discuti no presente trabalho, creio ser possível fazer uma correspondência entre a perspectiva etnográfica do letramento acadêmico e a análise que propus. Se de uma perspectiva etnográfica, as orientações não explicitadas sobre a escrita acadêmica são corretamente classificadas como aspectos "ocultos" do letramento acadêmico; de uma perspectiva histórico-discursiva - atenta, portanto, especificamente, a fatos de linguagem - esses aspectos poderiam, inversamente, ser concebidos como indícios de saberes que se dão a ler na opacidade dessa escrita.

Assim pensados, esses aspectos não seriam nem transparentes nem se apresentariam como efeito de ocultação, fosse ela voluntária ou involuntária. Com efeito, registra-se, nos textos, o que poderíamos chamar de um descompasso quanto à relação entre o dito e o presumido (VOLOSHINOV; BAKHTIN, 1976) num dado gênero. Como se sabe, a comunicação materializada em palavras (o dito) depende do presumido (de uma instância sociocultural mais ampla) que elas sugerem numa dada localização espaçotemporal. Especulo, a esse respeito, sobre a possibilidade de estender a ideia do presumido, necessário à constituição do sentido de um enunciado concreto, para o processo de constituição de um dado gênero, ou seja, o presumido necessário à constituição do sentido seria, também, necessário à constituição de um dado gênero do discurso.

Para alguém que se inicia num novo ambiente social, é sempre difícil alcançar o presumido da nova esfera de atividade em sua relação com a manifestação linguística correspondente, isto é, com os enunciados concretos de um gênero de discurso; dificuldade que, como mostra Street (2009), também atinge os responsáveis - supostamente hábeis nesse tipo de produção escrita - pelo letramento acadêmico nas universidades e também no Ensino 
Médio. Da parte dos alunos, as relações entre gêneros conhecidos (incluindo os presumidos que lhe são associados) e gêneros por dominar ocorrem com frequência e podem ser bons indicadores:

- de que, na constituição de um gênero, encontram-se, sempre, outros gêneros; e

- de que náo basta relacionar os gêneros do discurso com base, apenas, em suas materialidades linguísticas; é preciso, também, estabelecer relações entre os seus presumidos.

Da parte do professor, a atenção pode, como no exemplo de Street (2009), estar voltada mais para as relaçóes verbais entre gêneros do que para o presumido que lhes é atribuído no próprio contexto acadêmico, com a circunstância agravante de supô-lo como já conhecido pelos alunos. Nessas circunstâncias, é comum que os alunos sejam orientados a seguir certos percursos verbais sem que dominem, ainda, inteiramente, o presumido (do gênero) a que esses recursos estão associados. Pode-se, pois, dizer que, do ponto de vista da linguagem, é a desatenção à parte presumida do gênero que acaba levando aos chamados aspectos "ocultos" do letramento acadêmico.

No presente trabalho, investiguei registros de saberes na constituição de dois gêneros do discurso: o provérbio e a redação de vestibular. Procurei mostrar que o olhar dirigido ao processo de constituição de um gênero do discurso pode servir - feitas as adaptaçóes necessárias - para o trabalho pedagógico de detectar o momento do processo de escrita do escrevente, particularmente no que se refere ao gênero produzido por ele.

Nesse sentido, o tratamento da escrita em termos de práticas e de contextos de uso permite observar o processo de constituição dos gêneros do discurso e da própria escrita dos estudantes. Se as dificuldades do escrevente forem vistas, por exemplo, como registros do processo de apropriação de um dado gênero de discurso e não, simplesmente, como marcas de fragmentação ou de falta de coerência, pode-se, por meio delas, chegar a dados da história de contato do escrevente com o já-falado/ escrito. Tal preocupação contribuiria não para fechar os olhos para o que, habitualmente, consideramos como "erro", mas para buscar entender o processo de escrita do aluno e nele intervir. Náo se trata, portanto, de fazer vista grossa aos altos e baixos da produção escrita dos alunos, muitas vezes com o argumento falacioso de que essa atitude seria uma atitude respeitosa 
para com ele. Pelo contrário, significa ter acesso à história de contato do escrevente com o já-falado/escrito e compreender seu processo de escrita com atenção e acuidade. Ou seja, para ensinar a escrever, é preciso, antes de tudo, tomar conhecimento da escrita do aluno e, também, do que ele sabe sobre ela. No mais, é criar condiçôes didáticas locais - historicamente situadas, inclusive com base na própria escrita do aluno - que permitam que o escrevente possa exercitar o distanciamento de seu próprio texto, modo de potencializar leituras críticas, engendrando os fundamentos para a autocrítica. Naturalmente, o conhecimento da escrita do aluno não requer um trabalho restrito a um único indivíduo. Pode ser compartilhado entre vários alunos, como oportunidade oferecida a todos para que exercitem o distanciamento em relação às suas próprias escritas.

Da perspectiva do professor, investigar a circulação dialógica do escrevente pelo já-falado/escrito pode, portanto, ser ponto de partida:

- para selecionar apropriadamente o material didático a ser utilizado;

- para escolher e encadear atividades didáticas adequadas ao momento de desenvolvimento da escrita dos alunos; e, sobretudo,

- para cuidar da capacitaçáo do aluno a fim de que ele se torne um investigador de seu próprio texto.

Um encontro entre prática de pesquisa e ensino pode, pois, ser exemplificado pelo acesso a dados da relaçáo do escrevente com o já-falado/ escrito, privilegiando o processo de constituição de seu texto, o que auxilia na tomada de decisóes didáticas em sala de aula.

\section{Notas}

1 Cf., a respeito, a excelente crítica de Marcuschi (1994; 1995).

2 Refiro-me a práticas mnemônicas ligadas, por exemplo, ao conceito de quantidade. Em certas comunidades, recursos como o dos nós são uma maneira de lidar com o conceito de quantidade, constituindo, portanto, um tipo de letramento. No que se refere aos entalhes, eles são, talvez, mais notados do que os nós, já que são valorizados inclusive como arte (ainda que como arte "primitiva"), correspondendo ao trabalho realizado por meio de cortes em matérias duras. A pedra, a cerâmica, a 
madeira, mas também o vidro e o metal são matérias duras que servem de base para o entalhe. É interessante pensar no paralelo possível entre essas matérias e a matéria sonora da linguagem articulada. Naquelas, o corte prende-se a uma representação de um objeto ou de uma ideia; na matéria sonora, o corte da representação grafemática trabalha com o plano formal e não com o plano do conteúdo da linguagem.

3 O exemplo mais conhecido de relação intergenérica é aquele que, segundo Bakhtin (1992), envolve os chamados gêneros primários e secundários. Definindo os gêneros primários a partir do diálogo cotidiano, Bakhtin mostra que, na constituição de gêneros secundários (mais complexos e, em geral, segundo o autor, representados por gêneros escritos), pode haver a integração de gêneros primários. Bakhtin destaca a particularidade de que, na integração de gêneros primários em gêneros secundários, eles deixam de compor com as variáveis de tempo e espaço em que foram originalmente realizados para comporem com as variáveis espaçotemporais de seu novo contexto, o do gênero secundário que os integra. No presente trabalho, penso as relaçóes intergenéricas, ainda com base em Bakhtin, não apenas entre gêneros primários e secundários, mas, em princípio, entre quaisquer gêneros do discurso. Considerando que eles estão ligados sempre a esferas de atividade humana, a observação das relaçóes intergenéricas permite captar os cruzamentos entre diferentes práticas sociais ligadas àquelas esferas, fato que interessa de perto ao professor, já que ele precisa conhecer e acompanhar o processo de escrita de seu aluno.

4 Estes exemplos foram utilizados como material didático no curso de Teorias de Texto I, ministrado por mim para o $4^{\circ}$ ano do curso de Letras da Faculdade de Filosofia, Letras e Ciências Humanas da USP, no primeiro semestre de 2010.

5 Cf. a respeito, Lemos (1994).

6 Segundo WHITE (1992, p. 60, tradução minha), quando se pensa o discurso "como um aparato para a produção de significado mais do que meramente um veículo para a transmissão de informação sobre um referente extrínseco", o conteúdo do discurso "consiste tanto em sua forma como em qualquer informação que se possa extrair de sua leitura". Desse fato, o autor conclui que "alterar a forma do discurso 
pode não ser alterar a informação sobre seu referente explícito, mas é, certamente, alterar o significado produzido por ele."

7 Sobre a organização do heterogêneo da escrita, conferir o trabalho de Chacon (1998), baseado na crítica do ritmo de Henri Meschonnic (1982).

8 Esta classificação foi utilizada por Alves (2008).

\section{REFERÊNCIAS}

ABAURRE, M. B. M.; FIAD, R. S.; MAYRINK-SABINSON, M. L. T. Cenas de aquisição de escrita. Campinas, SP: Mercado de Letras/ABL, 1997.

ALVES, G. DE O. Recorrência de marcas proverbiais em textos de préuniversitários: tradição oral e alteridade. 2008. 66p. (Relatório final de iniciação científica CNPq-PIBIC) - Faculdade de Filosofia, Letras e Ciências Humanas, Universidade de São Paulo, 2008.

AFONSO, A. J. Os lugares da educação. In: VON SIMSON, O. de M.; PARK, M. B.; FERNANDES, R. S. (Org.). Educação não-formal: cenários da criação. Campinas, SP: Unicamp/Centro de Memória, 2001. p. 29-39.

BAJARD, É. Nova embalagem, mercadoria antiga. Educação e Pesquisa, São Paulo, v. 32, n. 3, p. 493-507, set. 2006. Disponível em: <http:// www.scielo.br/pdf/ep/v32n3/a05v32n3.pdf>. Acesso em: 25 jun. 2010

BAKHTIN, M. Estética da criação verbal. São Paulo: Martins Fontes, 1992.

BARRÉ-DE-MINIAC, C. Saber ler e escrever numa dada sociedade. In: CORRÊA, M. L. G.; BOCH, F. (Org.). Ensino de língua: representação e letramento. Campinas, SP: Mercado de Letras, 2006. p. 37-57.

BONVINI, E. Tradição oral afro-brasileira: as razões de uma vitalidade. Revista Projeto História, São Paulo, n. 22, p. 37-48, jun. 2001.

CHACON, L. Ritmo da escrita: uma organização do heterogêneo da linguagem. São Paulo: Martins Fontes, 1998. 
CORRÊA, M. L. G. O modo heterogêneo de constituição da escrita. São Paulo: Martins Fontes, 2004.

- Arranjos referenciais de tempo em textos de pré-universitários: letramento e oralidade. Revista Gragoatá, Niterói, n. 25, p. 75-94, jul. dez. 2008. Disponível em: <http://www.uff.br/revistagragoata/revistas/ gragoata25web.pdf $>$. Acesso em: 25 jun. 2010.

- A presença do modo de transmissão oral do saber na escrita de pré-universitários. In: Marçalo, M. J.; Lima-Hernandes, M. C.; Esteves, E.; Fonseca, M. do C.; Gonçalves, O.; Vilela, A.L., Silva. A. A. (Org.). Lingua portuguesa: ultrapassar fronteiras, juntar culturas. 1 ed. Évora (PT): Universidade de Évora (PT), 2010, v. Único, p. 150-159.

LEA, Mary R.; STREET, Brian V. The "Academic literacies" model: theory and applications, Theory Into Practice, Ohio, v. 45, n. 4, p. 368377, out. 2006.

LEMOS, C. T. G. de. A função e o destino da palavra alheia. In: BARROS, D. P. de; FIORIN, J. L. (Org.). Dialogismo, polifonia, intertextualidade: em torno de Bakhtin. São Paulo: EDUSP, 1994, p. 3743.

MARCUSCHI, L.A. Contextualização e explicitude na relação entre fala e escrita. Versão preliminar da conferência apresentada no I Encontro Nacional sobre Língua Falada e Ensino, na UFAL, Maceió (AL-Brasil): 14 a 18/03/94, p. $1-19$ (xerox do original).

. (1995) Oralidade e escrita. Texto da Conferência pronunciada no I COLÓQUIO FRANCO-BRASILEIRO SOBRE LINGUAGEM E EDUCAÇÃO. UFRN, 26-28 de junho, p. 1-17 (xerox do original).

MARTINS, W. A palavra escrita: história do livro, da imprensa e da biblioteca. Com um capítulo referente à propriedade literária. 3. ed. São Paulo: Ática, 2002.

MESCHONNIC, H. Critique du rytme: anthropologie historique du langage. Paris: Verdier, 1982.

OLSON, D. R. From utterance to text: the bias of language in speech and writing. Harward Educational Review, Cambridge, Massachusetts, v. 47, n. 3, p. 257-281, aug. 1977. 
ONG. W. Oralidade e cultura escrita: a tecnologização da palavra. Campinas, SP: Papirus, 1998.

POSSENTI. S. O eu no discurso do outro ou a subjetividade mostrada: sobre provérbios e análise do discurso. In: Os limites do discurso: ensaios sobre discurso e sujeito. Curitiba, PR: Criar ediçóes, 2002. p. 6173; p. 187-193.

\section{SEMINÁRIO DO GRUPO DE ESTUDOS LINGUÍSTICOS DO} ESTADO DE SÃO PAULO (GEL), 58., São Carlos. Anais... São Carlos, SP: UFSCAR, 2010.

STREET, B.V. Social literacies: criticial approaches to literacy in development, ethnography and education. London: Longman, 1995.

Perspectivas interculturais sobre o letramento. Revista Filologia e Lingüistica Portuguesa, São Paulo, n. 8, p. 465-488, 2006.

. "Hidden" Features of Academic Paper Writing. Working Papers in Educational Linguistics, Philadelphia, PA, v. 24, n. 1, p. 1-17, sept./ nov. 2009.

VOLOSHINOV, V. N.; BAKHTIN, M. M. Discurso na vida e discurso na arte: sobre poética sociológica. Tradução de Carlos Alberto Faraco e Cristóvão Tezza. New York: Academic Press, 1976. Tradução para uso didático. Texto originalmente publicado em russo, em 1926.

WHITE, H. El contenido de la forma: narrativa, discurso y representación histórica. Barcelona: Paidos, 1992. Disponível em: <http://www.scribd. com/doc/31205302/Hayden-White-El-contenido-de-la-forma-Narrativadiscurso-y-representacion-historica>. Acesso em: 25 jun. 2010. 


\section{Meetings between research practice and teaching: orality and literacy in the teaching of writing}

\begin{abstract}
This study starts with how the speech genre is constituted based on the core theory of intergeneric relations (Bakhtin, 1992). Types of literacy, orality and heterogeneity of writing are resources through which parodied proverbs on the Internet and in college board exam writings, as well as the use of different orders of temporalities for these writings are examined. Thus, productivity of the encounter between research and writing practices can be observed, even when recognizing that the theoretical-methodological treatment of the research object is not transfered as such to teaching activity.
\end{abstract}

Keywords: Orality. Writing. Teaching practice. Research.

\section{Encuentros entre la práctica de investigación y la enseñanza: oralidad y literacidad en la enseñanza de la escritura}

\section{Resumen}

En el presente texto se parte del proceso de constitución de los géneros discursivos, tomando como noción teórica central las relaciones intergenericas (BAKHTIN, 1992). Tipos de literacidad, oralidad y heterogeneidad de la escritura son los recursos por los cuales se investiga tanto el uso de proverbios parodiados en la internet y en las redacciones del curso de ingreso a la universidad (vestibular), como así también el uso de temporalidad de diferentes ordenes en el proceso de constitución de esas redacciones. Como resultado, se evidencia el encuentro entre la práctica de la investigación y la enseńanza, mismo que se reconozca que el tratamiento teórico - metodológico del objeto de investigación no se transfiere como tal para la actividad de enseñar.

Palabras claves: Oralidad. Escrita. Práctica de la enseñanza. Investigación.

\section{Manoel Luiz Gonçalves Corrêa}

Rua do Lago, 717

Cidade Universitária - São Paulo - SP/Brasil

CEP 05508-900

Telefone: 55-11-3091-4512 (Secretaria); 55-11-3091-2330 (fax trabalho); 55-113819-9026 (fax residencial).

E-mail: mcorrea@usp.br 